\title{
The Effect of Typographical Features of Subtitles on Nonnative English Viewers' Retention and Recall of Lyrics in English Music Videos
}

Farshid Tayari Ashtiani*

Iran-Europe Language Institute. Tehran, Iran

Corresponding Author: Farshid Tayari Ashtiani, E-mail: Ashtiani.farshid@gmail.com

\section{ARTICLE INFO}

Article history

Received: June 07, 2017

Accepted: July 29, 2017

Published: December 01, 2017

Volume: 6 Issue: 7

Special Issue on Language \& Literature Advance access: September 2017

Conflicts of interest: Non

Funding: None

\begin{abstract}
The goal of this study was to test the effect of typographical features of subtitles including size, color and position on nonnative English viewers' retention and recall of lyrics in music videos. To do so, the researcher played a simple subtitled music video for the participants at the beginning of their classes, and administered a 31-blank cloze test from the lyrics at the end of the classes. In the second test, the control group went through the same procedure but experimental group watched the customized subtitled version of the music video. The results demonstrated no significant difference between the two groups in the first test but in the second, the scores remarkably increased in the experimental group and proved better retention and recall. This study has implications for English language teachers and material developers to benefit customized bimodal subtitles as a mnemonic tool for better comprehension, retention and recall of aural contents in videos via Computer Assisted Language Teaching approach.
\end{abstract}

Key words: Typographical Features, Lyrics, Retention And Recall, Music Video, Song, Bimodal Subtitles

\section{INTRODUCTION}

Music and songs in any language are like chains that link people regardless of their language, race, and nation and any other discriminators. As a matter of the fact that English language is used as a lingua franca among people around the world, songs in this language become widespread easier and faster than any songs in any other languages. When song tracks are produced in music videos, they are transformed into an embedded context that activates another human intelligence, the visual or spatial intelligence (Gardner, 1983), attracts more attention, provides more comprehensibility and creates more sense of appreciation. Over and above, there is another extra-musical factor that could create more amount of comprehension, appreciation and attention, it is subtitles. There are three types of subtitling in videos as mentioned by Karakas \& Saricoban (2012): (1) Bimodal subtitling which holds English dialogues and English subtitles, (2) Standard subtitling that contains English dialogues and first language subtitles, (3) Reversed subtitling carrying first language dialogues and English subtitles.

Mateo (2007) (cited in Silveira \& Diaz, 2014) says although reading subtitles may require more cognitive efforts, they can provide a rich, active, and enjoyable experience that contribute to increased attendance. Subtitles as visual stimuli in music videos showcase the value of song lyrics and help nonnative English speakers a lot to understand the lyrics more and make a better connection with the song to enjoy. On the opposite, from a pedagogical perspective, there are negative comments and research results as well. For instance, Zanon (2006) believes that the drawback of subtitling is that learners may focus much in reading the subtitles not to miss any part in the dialogue which will evolve a habit of reliance on subtitles; however, he points to the advantages such as motivating learners and making them secure and self-confident. On one hand, some believe that subtitles of any type could cause distraction in comprehension or learning, on the other hand, there are various studies in the literature that repudiate this assumption, such as Vanderplank (1988) who states "far from being a distraction and a source of laziness, subtitles might have a potential value in helping the learning acquisition process by providing learners with the key to massive quantities of authentic and comprehensible language input".

Significance of subtitles has been proved and corroborated by many scholars and researchers even from the nineteenth century to the recent years. Reese \& Davie (1987) proved the importance of captions and subtitles for directing a careful attention and cuing recall of specific contents. Karakas \& Saricoban (2012) state that although language learners have difficulty in comprehension of video materials in the target language, they could be equipped with subtitles, either first or target language, in order to facilitate the amount of comprehensibility of the videos. Moreover, Parks (1994) states "students using captioned materials show significant improvement in reading comprehension, listening comprehension, vocabulary acquisition, word recognition, 
decoding skills, and overall motivation to read". Vanderplank (1988) states that employing subtitles furnishes immediate feedback and consequently positive reinforcement to contribute in emerging a sense of security on learners and helping them to feel prepared to watch videos and films in the target language without subtitles in the long run.

The usability of subtitles for learners of a foreign language as a support for comprehension and discovering new words is evidenced by different researchers such as Danan (1992) who confirms the major effects of visual associations on memory and the mnemonic power of imagery. For comprehending linguistic inputs, learning, retaining and recalling, the first step, as Read (2004) confirms, is to recognize the lexical items in the process which are lyrics in the music videos in this study. Moreover, Wesche \& Paribakht (1996), cited in Fazilatfar \& Ghorbani (2011), state three levels of learning lexical items which the first one is initial recognition, then comprehension of denotation and connotation and lastly the ability to produce. Accordingly, to facilitate learning and comprehending words and lyrics in music videos, the first step is transcribing them through captions that using subtitles is the best and most fruitful approach approved in the literature. Some of the outstanding benefits of subtitles based on King (2002) (cited in Zanon, 2006), are listed below:

- Their use bridges the gap between reading and listening skills.

- Students can learn to process text in the foreign language rapidly and improve rapid reading, by trying to keep up with the subtitles that accompany the dialogues.

- Students can learn how to pronounce many words, consciously and unconsciously.

- Subtitles allow learners to follow the plot easily.

- Learners can develop word recognition skills.

- Captions can reinforce the understanding of English context-bound expressions, and help learners to acquire new vocabulary and idioms.

- Students can understand humor, such as jokes, that would be hard to recognize without the help of the captions. Humor can be a difficult, but rewarding subject for the language classroom (Gillespie \& Lonergan, 1989), and subtitles help to understand it, enhancing the enjoyable character of the activity.

- Subtitles can enhance students' concentration in following lines.

- $\quad$ Finally, subtitles can motivate students to study English outside the classroom context, especially by watching TV and cinema, listening to the original dialogues.

Even though many research and studies have been carried out in the realm of subtitles and most of the previous studies have acknowledged the utility of subtitles in comprehension and learning, still there exist a gap amid the studies to investigate the effects of typographical features of subtitles such as size, color and position. The utilities of subtitles in many aspects such as meaning comprehensibility, vocabulary learning and listening comprehension have been approved but, to the best of our knowledge, almost no studies have examined the effects of customized subtitles on retention and recalling aural contents in videos such as lyrics in music videos.

The present study takes it significance from some aspects affirmed by previous studies and some other new aspects, which are not studied yet in the literature. Amid all the research done in subtitling, no research could be found to have studied the typographical features of subtitles and their effects on viewers' retention and recall of aural messages in a video. In any written formats such as video subtitles, image captions, reading texts, slogans or maxims, warning or marketing signs, etc., typographical features such as size, colors and positions are very important in terms of grabbing the attentions, conveying the meaning, and even prioritizing the words in the text to be seen, red and consolidated in mind. In this study, we focus on subtitles but in terms of their size, color and position. We essayed to demonstrate the significance of typographical features of subtitles, transcribed lyrics, in a music video to prove the value of typo graphics and the effects they could bring about on viewers' mind to read and understand the lyrics in the least possible time and recalling later.

The other significance of this research could have implications for singers and music videos directors to consider their English non-native fans of their songs who watch their favorite music videos but cannot fully recognize and understand the lyrics to recite later. By subtitling the lyrics, especially in bimodal customized type, they can showcase the lyrics.

Throughout this study we attempt to show the importance of typographical characteristics of subtitles on nonnative viewers' comprehension, retention and recall of lyrics in a music video. We compare two kinds of subtitles, simple and customized, in a music video to find the differences. Subtitles were served as a pedagogic technique and a mnemonic tool to enhance English language learners' ability to recognize and recall the lyrics in the music video. This research investigates the significance of typo graphics of subtitles, bimodal type, and its effects on nonnative English viewers' retention and recall of lyrics in a music video.

\section{REVIEW OF LITERATURE}

There are myriad studies which have probed the effects of subtitles and captions on different skills and components of language including listening, reading and vocabulary learning. Generally, almost all of the former studies in the literature have maintained that subtitles are influential rigs to be added to the video materials for learning vocabulary, improving reading and listening comprehension but they differ depending on the type of subtitles including bimodal, standard and reversed. However, there are many other studies which repudiate the positive impacts of subtitles as they are distractions to the pictures, they cause laziness in listening and reliance on reading, or they lessen the sense of appreciation in the video and audio. One of those research is a study in psychology of music that its result showed an expressivity attenuation in subtitled conditions. The purpose of the study done by Silveira \& Diaz (2012) was to determine what effect a variety of listening conditions (audio, audio + video, audio 
+ video with subtitles) would have on listeners' perception of expressivity. It appeared that listeners' magnitude of response was attenuated under the subtitles condition. They speculated that subtitles may had served as a distraction inhibiting listeners' perception of expressivity moments. On the contrary, the subtitles conditions evidenced the highest level of focus of attention and this could connote that listeners had concentrated on the subtitles rather than the music. In this regard, LaBerge (1995) (cited in Silveira \& Diaz, 2014) has stated that when top-bottom controls are too strong and attentional shifts are inhibited (i.e. focusing on subtitles) characteristics of the music may go unnoticed or not fully realized. But considering the pedagogical aspects of using subtitles, there are miscellaneous studies that approve the benefits of subtitles in videos. A study investigating the effects of subtitled videos on foreign language learning by Danan (2006) concluded revised subtitling could be the most constructive manipulation on videos to enhance learning in a comparison with no subtitling and standard subtitling. In other studies such as Baltova (2006) it was approved that bimodal subtitled videos are fruitful materials to enhance L2 learners' comprehension and vocabulary learning. In a research done by Zarei \& Zarnani (2009) on some Iranian university students' English vocabulary recognition and recall to check the effects of three kind of subtitling, bimodal, standard and reversed and the results showed that the students' performance in standard and bimodal groups was significantly different from the reversed group. He proved that the most influential type of subtitling is bimodal subtitles for vocabulary recognition and recall. Then, standard subtitles and the least effective subtitle type was the reversed one.

The effectiveness of reversed subtitled movies in vocabulary learning has been approved by different researchers such as Kazemi \& Zarei (2015) concluding that "subtitled movies with Persian soundtrack and English subtitles are more suitable for EFL learners in Iran because the participants can be exposed to more channels of information". Even in old studies like Holobow, N. E (1984) or new ones like Abdolmanafi Rokni \& Jannati Ataaee (2014) the same conclusion, the effects of reversed subtitling, have been drawn confirming that reading $\mathrm{L} 1$ subtitles is not a distraction for the viewers while hearing the English dialogues. In the study done by Gorgian (2014), different types of subtitles were examined on participants' vocabulary learning that its results demonstrated the superiority of reversed subtitling over standard and no subtitling to improve the learners' comprehensibility of unknown words through eight sessions of instruction and practice. Grignon, Lavaur, Blanc (2005) conducted their research by comparing three versions of a film including subtitled, dubbed and the original one without subtitles to compare the effects of the versions on film comprehension. They came into this conclusion that dubbed and subtitled films engendered a superior performance compared to the original film. Following the fruitful utility of subtitles in language learning, Neuman \& Koskinen (1992), reached in the results that the participants who watched captioned videos learned more new words. A master thesis by Kovacs (2013) from the Massachusetts Institute of Technology aimed to improve vocab- ulary learning while foreign-language learners are watching foreign-language videos and achieved desired results of an increase in vocabulary acquisition and no decrease in comprehension or enjoyment.

There are many research in the literature confirming the effectiveness and advantages of subtitles and captions in reading, and studies that have investigated the impacts of manipulations in subtitles on reading performance. The significance of typographical features of text has been underscored by researchers since old times such as Tinker \& Paterson (1930) who investigated typographical factors influencing speed of reading. They found in their results that black on white, grass green on white, luster blue on white, and black on yellow provide good legibility. Tulip-red on yellow, tulip red on white provide fair legibility, and grass green on red, chromium orange on black, chromium orange on white, tulip red on green, black on purple providing poor legibility. They also drew that a maximum brightness-contrast between text and background is satisfactory for the greatest legibility. In a study by Wu \& Yuan (2003), the effect of highlighting and text color coding was examined on reading performance. Through this research leading to know how different types of highlighting and text display color combinations could affect reading performance, the researcher drew in the results that highlighting is able to significantly enhance searching and the best highlighting tool was color. When different color combinations were applied to textual display, the speed and performance of readers were higher. Matthews (1988) conducted his research to see the influence of color on CRT reading performance and subjective comfort under operational conditions. He investigated the reports and performance of comfort at the time of proof-reading text displayed on a CRT as a function of the text/background color. He concluded that colors which are at the extremes of the spectrum (red and blue) produced poorer reading performance and those colors from the middle spectrum showed less symptoms of discomfort. In the research conducted by Gradisar, Humar \& Turk (2006) the factors affecting the readability of colored text in computer displays were investigated. They gave $30 \mathrm{col}-$ or combinations (background and text) to their participants to check the differences in speed of reading. Their results showed no statistically significant difference in readability. They quoted from Tinker \& Paterson (1930), and Boyarski et al (1998) that the speed of reading relies on multiple factors such as font selection, font size and color combination. So, reasoned that reading is a very complex process that is influenced by many interrelated factors. In a very recent study by Olurinola et al (2015), the effects of color in learning on retention rate was examined. The research design was a single posttest having an independent variable, color at two levels of congruent (colors corresponding to the words) and incongruent (colors not related to the words) firstly proposed by Stroop (1935). The scores were based on the number of words recalled. The results showed that the groups exposed to the congruent colors performed better than those exposed to the incongruent colors. Therefore, Olurinola and his co-authors recommended the material developers more attention to the colors and their effects on learning. 
Regarding the type of subtitles exerted in this research, Borras \& Lafayette (1994) proved the effects of bimodal subtitling in EFL/ESL learners to associate the aural and written forms of the words more facile and faster. Their results showed the potential value of captions assist learners not only in comprehending the authentic linguistic input but also producing correct output. Employing bimodal subtitles could also be supported with the results of a study by Baltova (2006) in which he found and discussed bimodal subtitled videos are effective to enhance L2 learners' understanding the dialogues completely and learning vocabularies because a simultaneous exposure to spoken language, written text and pictures all conveying the same message is provided.

The purpose of this study, presuming the superiority of positive effects of subtitled conditions over non subtitled conditions in vocabulary learning and retention, is to compare simple bimodal subtitles with customized bimodal subtitles different in size, color and position in retention and recall of the lyrics in an English music video. In order to achieve this goal, the researcher formed a question and proposed his hypothesis to target the aim of his research.

\section{Research Question}

1. Is there any significant difference between a simple bimodal subtitled music video and a customized bimodal subtitled music video in non-native English viewers' retention and recall of lyrics in music videos?

\section{Research Hypothesis}

H1. The researcher set out a directional hypothesis on superiority of the effects of the customized subtitled music video over the simple subtitled music video in nonnative English viewers' retention and recall of the lyrics.

\section{METHODOLOGY}

The present research is a quantitative and correlational research in which there was no treatment but manipulations in the material for the experimental group. In order to clarify the research methodology sections, the participants, materials, procedure and data analysis are described below.

\section{Participants}

Hatch \& Lazaraton (1991) state that the sample size must contain a number of participants that the quantitative data analysis yields a distribution of range of scores. They suggest a minimum of 30 participants; however, we know that the more samples the more reliability. The sampling method for choosing the participants in this research was based on one criterion sampling; a threshold level of English language proficienc, intermediate level, to have homogenous participants.

We administered our tests in 9 different classes with a total of 64 adult students. The participants were English language learners in a language institute in Tehran-Iran as nonnative speakers of English in an expanding circle of learning context (Iran) where English is spoken as a foreign language. We assigned first 4 classes composed of 31 students as our control group and 5 other classes composed of 33 students as the experimental group. The classes were mixed and students over 20 years old.

\section{Materials}

In order to examine the effects of bimodal subtitles in music videos on viewers' retention and recall of the lyrics and recognizing the differences between simple and customized subtitles, we purposefully chose an English music video that was appropriate for the focus of our study, subtitled lyrics, as the only independent variable through the strategies of purposeful sampling which Patton (2002) distinguished. Via intensity sampling that involves "excellent or rich examples of the phenomenon of interest but not highly unusual cases", we handpicked among those music videos which were rich in lyrics to be subtitled and assisting us to elicit more valid data from the participants to increase and maintain the internal validity of the research. Accordingly, we chose the Style music video by Taylor Swift from the album 1989 released in 2014 and added two kinds of subtitles to it by Adobe software After Effects, version CC 14.0 and created two versions of the original music video. The video with simple subtitles was used as the control group's input and the video with customized subtitles was employed as the experimental group's manipulated input.

In order to check the participants' retention and recall of the lyrics, the researcher prepared and administered a post hoc cloze test including 31 blanks extracted from the lyrics of the song. Cloze is derived from the concept of "Closure" well known in Gestalt psychology and became very infl ential in the area of visual perception. It is also known as holistic pattern or theory of the Whole.

\section{Procedure}

We produced two subtitling versions of our chosen music video. One with common simple subtitles and the other with customized subtitles in color, size and position. In adding-the-subtitles phase in the software, we chunked the subtitles phrase by phrase to be in a harmony with the vocal. For the test, we designed a cloze test extracted from the lyrics. According to Taylor (1953), cloze procedure was defined as "any passage of appropriate length and difficulty with every nth word deleted'. Researchers believe every $5^{\text {th }}$ or $7^{\text {th }}$ word deletion have shown better psychometric characteristics. So, to find the number of deletions, first, we counted the words of the lyrics in Microsoft Word without onomatopoeias, redundancies and the repeated verses to prevent the probable repetition of words. There were 222 words. Then, we divided the total number of the words by 7 that equaled 31.71 . Since the passage was lyrical and not a simple text, we did some purposeful changes in making the cloze test to have more valid blanks by exchanging those words which were not suitable to be deleted like prepositions or pronouns with nouns or main verbs before or next to them. So, 31 words were determined to be deleted from the passage. For doing 
the experiment, the researcher looked in a language institute for intermediate classes. We played the simple subtitled music video at the beginning of 9 different classes in a language institute comprising of 64 students totally. Then, we administered the cloze test at the end of their classes after one hour and a half. The answer sheets were collected and scores extracted. In the next session, after 2 days, the same music video was played for the second time in the same 4 classes participated in the first test and again the same cloze test was administered to them at the end of their classes, then the answer sheets were collected as the scores of control group along with their first test scores. For the other 5 classes participated in the first test, the second version of the music video, customized subtitled, was played at the beginning of their classes, then the same cloze test was administered at the end of their classes. Answer sheets were collected as the scores of experimental group along with their first test scores. Fortunately, our two test sessions in each group did not suffered from any mortality effects.

Finally, to check the answers in the cloze test there were three methods of Exact Word, Acceptable Word and Weighted Response. Since we had original song lyrics as the answer key, we applied Exact Word method for scoring the answers.

\section{Data Analysis}

Having gathered the scores in each test which were out of 31 , we distributed them in three levels of Low, Average and High for both groups. Scores below 10 were labeled Low, between 11 and 21 Average and above 22 High. The frequency and percentage of scores in both tests were calculated and at the end of each testing phase, the mean scores of the two groups were compared through an independent T-test to show if there was any significant di ference.

\section{RESULTS}

\section{Descriptive Statistics}

The number of the participants involved in this research were 64 adult students from 9 intermediate classes and distributed to two groups randomly. 33 in the experimental group and 31 in the control group. Their test scores in two cloze tests were our quantitative variables. The descriptive statistics of the variables including average, standard deviation, maximum and minimum scores are presented separately in Table 1.

The scores were divided into three levels of Low (0-10), Average (11-21) and High (22-31) which Tables 2-5 demon- strate the frequency and percentage of scores in our three score-levels, and separately in each test.

\section{Normality of the Distribution}

Prior to applying the statistical tests, we examined the equality of continuousness of the variables through nonparametric tests, Kolmogorov-Smirnov test, to check the normality of the distribution. Table 6 shows the results.

Since the $\mathrm{P}$ value in each of the two tests is higher than 0.05 , it is proved that the distribution of the scores is in a normal status. Therefore, we used parametric tests such as independent $\mathrm{T}$-Test to reach the final results in comparing scores of the two groups.

\section{Inferential Statistics}

In this part of the data analysis we compared the average score of the two groups in each test. To do so, we used an independent T-test that Tables $7 \mathrm{a}$ and $7 \mathrm{~b}$ illustrate the results in test 1 and test 2 respectively.

The averages of test scores in the first round of the test were 10.84 and 11.42 respectively for the control and experimental group, which show no significant difference between the groups. But the average of test scores in the second test was 19.76 in the experimental group and 11.97 in the control group, which demonstrates a significant difference between the two groups. It proves that scores noticeably improved in the second round of the test in the experimental group for which the customized subtitled version of the music video was displayed.

\section{CONCLUSION}

With a review to the literature concerning the effects of subtitles of any mode (standard, reversed \& bimodal), we see a vast research repertoire such as (Holobow, N. E, 1984. Neuman \& Koskinen, 1992. Grignon, Lavaur, Blanc, 2005. Danan, 2006. Baltova, 2006. Zarei \& Zarnani, 2009. Kovacs, 2013. Kazemi \& Zarei, 2015. Etc) that confirms the benefits of subtitles in different components of language learning and so do the results of our present research. The use of subtitles engenders multi-sensory processes when mind interacts with audio (sounds), video (images) and dialogue transcriptions (subtitles) simultaneously. Pavio (1971) says that the number of meaningful signals associated to the audio message increases when related images and pictures are added. Also, Lozanov (1978) asserts that

Table 1. Descriptive statistics of variables

\begin{tabular}{llcccc}
\hline Group & Test & Average & Standard deviation & Minimum score & Maximum score \\
\hline Experimental group & Test 1 & 11.42 & 4.15 & 5 & 20 \\
& Test 2 & 19.76 & 4.69 & 8 & 26 \\
Control group & Test 1 & 10.84 & 4.06 & 5 & 19 \\
& Test 2 & 11.97 & 4 & 6 & 20 \\
Total & Test 1 & 11.14 & 4.08 & 5 & 20 \\
& Test 2 & 15.98 & 5.85 & 6 & 26 \\
\hline
\end{tabular}


Table 2. Frequency of test scores in test 1 (experimental group)

\begin{tabular}{llc}
\hline Variable & $\begin{array}{l}\text { Levels of } \\
\text { variables }\end{array}$ & Frequency (\%) \\
\hline $\begin{array}{l}\text { Experimental group } \\
\text { scores in the first test }\end{array}$ & Low (0 to 10) & $16(48.5)$ \\
& $\begin{array}{l}\text { Average (11 to 21) } \\
\text { High (22 to 31) }\end{array}$ & $17(51.5)$ \\
& & $0(0)$ \\
\hline
\end{tabular}

Table 3. Frequency of test scores in test 2 (experimental group)

\begin{tabular}{llc}
\hline Variable & $\begin{array}{l}\text { Levels of } \\
\text { variable }\end{array}$ & Frequency (\%) \\
\hline $\begin{array}{l}\text { Experimental group } \\
\text { scores in the first test }\end{array}$ & Low (0 to 10) & $1(3)$ \\
& Average (11 to 21) & $19(57.6)$ \\
& High (22 to 31) & $13(39.4)$ \\
\hline
\end{tabular}

Table 4. Frequency of test scores in test 1 (control group)

\begin{tabular}{llc}
\hline Variable & $\begin{array}{l}\text { Levels of } \\
\text { variable }\end{array}$ & Frequency (\%) \\
\hline $\begin{array}{l}\text { Experimental group } \\
\text { scores in the first test }\end{array}$ & Low (0 to 10) & $15(48.4)$ \\
& $\begin{array}{l}\text { Average (11 to 21) } \\
\text { High (22 to 31) }\end{array}$ & $16(51.6)$ \\
& & $0(0)$ \\
\hline
\end{tabular}

Table 5. Frequency of test scores in test 2 (control group)

\begin{tabular}{llc}
\hline Variable & $\begin{array}{l}\text { Levels of } \\
\text { variable }\end{array}$ & Frequency (\%) \\
\hline $\begin{array}{l}\text { Experimental group } \\
\text { scores in the first test }\end{array}$ & Low (0 to 10) & $13(41.9)$ \\
& $\begin{array}{l}\text { Average (11 to 21) } \\
\text { High (22 to 31) }\end{array}$ & $18(58.1)$ \\
& & $0(0)$ \\
\hline
\end{tabular}

Table 6. Normality of scores distribution

\begin{tabular}{lccc}
\hline Variable & Statics & $\boldsymbol{P}$ value & Results \\
\hline Test 1 & 0.106 & 0.070 & Normal \\
Test 2 & 0.088 & 0.200 & Normal \\
\hline
\end{tabular}

the balance between both hemispheres in a musical context of language learning makes the learner more receptive and the process more facilitative for learning new knowledge and skills. Having our research directional hypothesis approved, we conclude that over and above the suitability of the modality of subtitles, the typographical features of subtitles (color-size-position) have also significant effects on comprehension, retention and recall of the contents and message. However, the segmentation of texts is important and effective as well. In a study done by Rajendran et al (2001), the results yielded by eye movement tracking techniques showed that different styles of text segmentation elicit different viewing behaviors. Therefore, segmenting the lyrics word by word, chunked by phrase or chunked by verse could cause different impacts on viewers' perception, retention and recall. In this research, we realized that subtitling the lyrics in English music videos and customizing the subtitles in color, size and positions on video catch a considerable amount of attention and cause more comprehension of the lyrics and durable retention and recall especially in nonnative English viewers. As a result of the second round of the test, we found that the more the music video with subtitles is watched by English nonnative viewers, the more comprehension, retention and recall of the lyrics are occurred. But if watching the music video is repeated twice and more, the effects of customized subtitles appear much more than the simple subtitles. Hence, we can generalize that over and above the advantages of subtitled context that is proved by many former studies, typographical features of subtitles could strengthen the effects of subtitles in conveying the meaning, leading the viewers' attention to a specific part of the sentence such as a word, facilitating embedding and consolidating the message (dialogue, speech, lyrics, etc.) in viewers' mind and motivating the viewers to watch the videos that may be difficult to understand or less interesting to keep attention on.

\section{FURTHER RESEARCH}

This research investigating the effects of typographical features of subtitles on viewers' comprehension, retention and recall of contents and message could be pursued in other types of English videos such as TV commercials in international satellite TV stations such as $\mathrm{CNN}, \mathrm{BBC}$, and CNBC etc. in which the advertisements must convey the message

Table 7a. Independent t-test in test 1

\begin{tabular}{lllcccc}
\hline Population & Variable & Groups & Average & Standard deviation & $\boldsymbol{t}$ & Significance \\
\hline Intermediate students & Cloze test scores & Experimental & 11.42 & 4.146 & 0.570 & 0.570 \\
& & Control & 10.84 & 4.059 & & \\
\hline
\end{tabular}

Table 7b. Independent t-test in test 2

\begin{tabular}{lllcccr}
\hline Population & Variable & Groups & Average & Standard deviation & $\boldsymbol{t}$ & Significance \\
\hline Intermediate students & Cloze test scores & Experimental & 19.76 & 4.691 & $7.124 * *$ & 0.001 \\
& & Control & 11.97 & 4.004 & & \\
\hline
\end{tabular}


to a wide range of viewers across the globe in a very limited time like few seconds.

\section{REFERENCES}

Abdolmanafi Rokni, S.J, Jannati Ataee, A. (2014). Movies in EFL Classrooms: With or Without Subtitles. The Dawn Journal. 3 (1). [Online] Available https://pdfs.semanticscholar.org/1c05/2301627318561e44c12716a9c38d5096fa56.pdf

Arakas. A., Saricoban. A. (2012). The Impact of Watching Subtitled Animated Cartoons on Incidental Vocabulary Learning of ELT Students. Teaching English with Technology, 12 (4), 3-15. [Online] Available cejsh.icm.edu. $\mathrm{pl} /$ cejsh/element/bwmeta1.element.desklight./c/ARTICLE1.pdf

Bailey, K. M., Hatch, E., Lazaraton, A. (1994). The Research Manual: Design and Statistics for Applied Linguistics. TESOL Quarterly 28 (1), 209. https://doi. org/10.2307/3587214

Baltova, I. (1999). Multisensory Language Teaching in a Multidimensional Curriculum: The Use of Authentic Bimodal Video in Core French. The Canadian Modern Language Review, 56 (1), 31-48. https://doi.org/10.3138/ cmlr.56.1.31

Borras I., \& Lafayette, R.C. (1994). Effects of multimedia courseware subtitling on the speaking performance of college students of French. The Modern Language Journal, 78 (1), 61. https://doi.org/10.2307/329253

Danan. M. (1992). Reversed Subtitling and Dual Coding Theory: New Directions for Foreign Language Instruction," Language Learning, 42 (4), 497-527. https://doi. org/10.1111/j.1467-1770.1992.tb01042.x

Gardner, H. (1999b). The disciplined mind. (Chapter one). Simon \& Schuster Publication. ISBN-13: 978 0684843247

Garza. T. J. (1991). Evaluating the Use of Captioned Video Materials in Advanced Foreign Language Learning. Foreign Language Annals, 24 (3), 239-258. https://doi. org/10.1111/j.1944-9720.1991.tb00469.x

Gillespie, J., \& Lonergan, J. (1986). Video in Language Teaching. The Modern Language Journal, 70(2), 167. Doi: $10.2307 / 327326$

Gorjian, B. (2014). The Effect of Movie Subtitling on Incidental Vocabulary Learning among EFL Learners,' International Journal of Asian Social Science, 4 (9), 1013-1026. [Online] Available: http://www.aessweb. com/download.php?id=2886

Holobow, N.E, Lambert, W.E, Sayegh, L. (1984). Pairing Script and Dialogue: Combinations That Show Promise for Second or Foreign Language Learning. Language Learning, 34 (4), 59-74. https://doi. org/10.1111/j.1467-1770.1984.tb00352.x

Kazemi, S. A, Zarei, L. (2015). A Relook at the Efficacy of Persion and English Subtitled Movies on the Improvement of EFL Incidental Vocabulary Retention. European Journal of Academic Essays 2 (11), 43-50.

ISSN (online): 2183-1904. [Online] Available: euroessays. org/wp-content/uploads/2015/12/EJAE-471.pdf
King, J. (2002). Using DVD Feature Films in the EFL Classroom. Computer Assisted Language Learning, 15 (5), 509-523. https://doi.org/10.1076/call.15.5.509.13468

Kovacs, G (2013). Multimedia for Language Learning. S.B., Massachusetts Institute of Technology. http://hdl.handle. net/1721.1/85217

Gillespie, J., \& Lonergan, J. (1986). Video in Language Teaching. The Modern Language Journal, 70 (2), 167. Doi: $10.2307 / 327326$

Grignon, P., Lavaur, J. M., Blanc, N. (2005). The Effects of Subtitles on Film Understanding. [Online] Available: https://kamiresearching.wordpress.com/2009/10/12/ the-effect-of-subtitles-on-film-understanding-200

Mateo M. (2007b). Subtitling today: New uses, attitudes and developments. Linguistica Antverpiensia New Series - Themes in Translation Studies, 6: 135-154. [Online] Available: https://lans-tts.uantwerpen.be/index.php/ LANS-TTS/article/view/184

Matthews, M.L. (1988). The influence of color on CRT reading performance and subjective comfort under operational conditions. https://doi.org/10.1016/00036870(87)90140-2

Neuman, S. B. Koskinen. P. (1992). Captioned Television as Comprehensible Input: Effects of Incidental Word Learning from Context for Language Minority Students. Reading Research Quarterly, 27 (1), 94. https://doi. org/10.2307/747835

Olurinola et al (2015). Color in Learning: It's Effect on the Retention Rate of Graduate Students. Journal of Education and Practice. 6 (14). [Online] Available: files.eric ed.gov/fulltext/EJ1080132.pdf

Parks, C. (1994). Closed Captioned TV: A Resource for ESL Literacy Education", in Eric Digest (ED372662). Washington DC. [Online] Available: http://www.ericdigests. org/1995-1/tv.htm.

Patton, M. Q. (2002). Qualitative research and evaluation methods ( $3^{\text {rd }}$ ed). Thousand Oaks, CA: Sage Publications.

Read, J. (2004). Research in Teaching Vocabulary. Annual Review of Applied Linguistics. 24, 146-161. https://doi. org/10.1017/s0267190504000078

Rajendran. D.J et al (2001). Effect of Text Chunking on Subtitling: A Quantitative and Qualitative Examination. Perspectives. 21 (1), 5-21. https://doi.org/10.1080/0907 676x.2012.722651

Silveira, J. Diaz, F. (2014). The Effects of Subtitles on Listeners' Perception of Expressivity. Psychology of music. 42(2): 233-250. Sage https://doi. org/10.1177/0305735612463951

Tinker M.A, \& Paterson, D. G. (1931). Studies of typographical factors influencing speed of reading. VII. Variations in color of print and background. Journal of Applied Psychology, 15 (5), 471-479. http://dx.doi.org/10.1037/h0076001

Vanderplank, R. (1988). The Value of Teletext Sub-Titling in Language Learning. ELT Journal, 42 (4), 272-281. https://doi.org/10.1093/elt/42.4.272

Wesche, M. \& S.T. Paribakht, S. (1996). Assessing Second Language Vocabulary Knowledge: Breadth and Depth. 
Canadian Modern Language Review, 51, 13-40.

Wu. J \& Yuan. Y. (2003). Improving Searching and Reading Performance: The Effect of Highlighting and Text Color Coding. Information and Management, 7: 617-637. Doi: 10.1016/S0378-7206(02)00091-5

Zanon. N. T. (2006). Using Subtitles to Enhance Foreign Language Learning. Porta Linguarum 6, 41-52. ISSN:
1697-7467. [Online] Available: www.ugr.es/ portalin/ articulos/PL_numero6/talavan.pdf

Zarei, A. A. Zarnani, P. (2012). The Effect of Bimodal, Standard, and Reversed Code Mixing on L2 Vocabulary Recognition and Recall. International Journal of Applied Linguistics and English Literature. 1 (4), 183-190. https://doi.org/10.7575/ijalel.v.1n.4p.183

\section{APPENDIX}
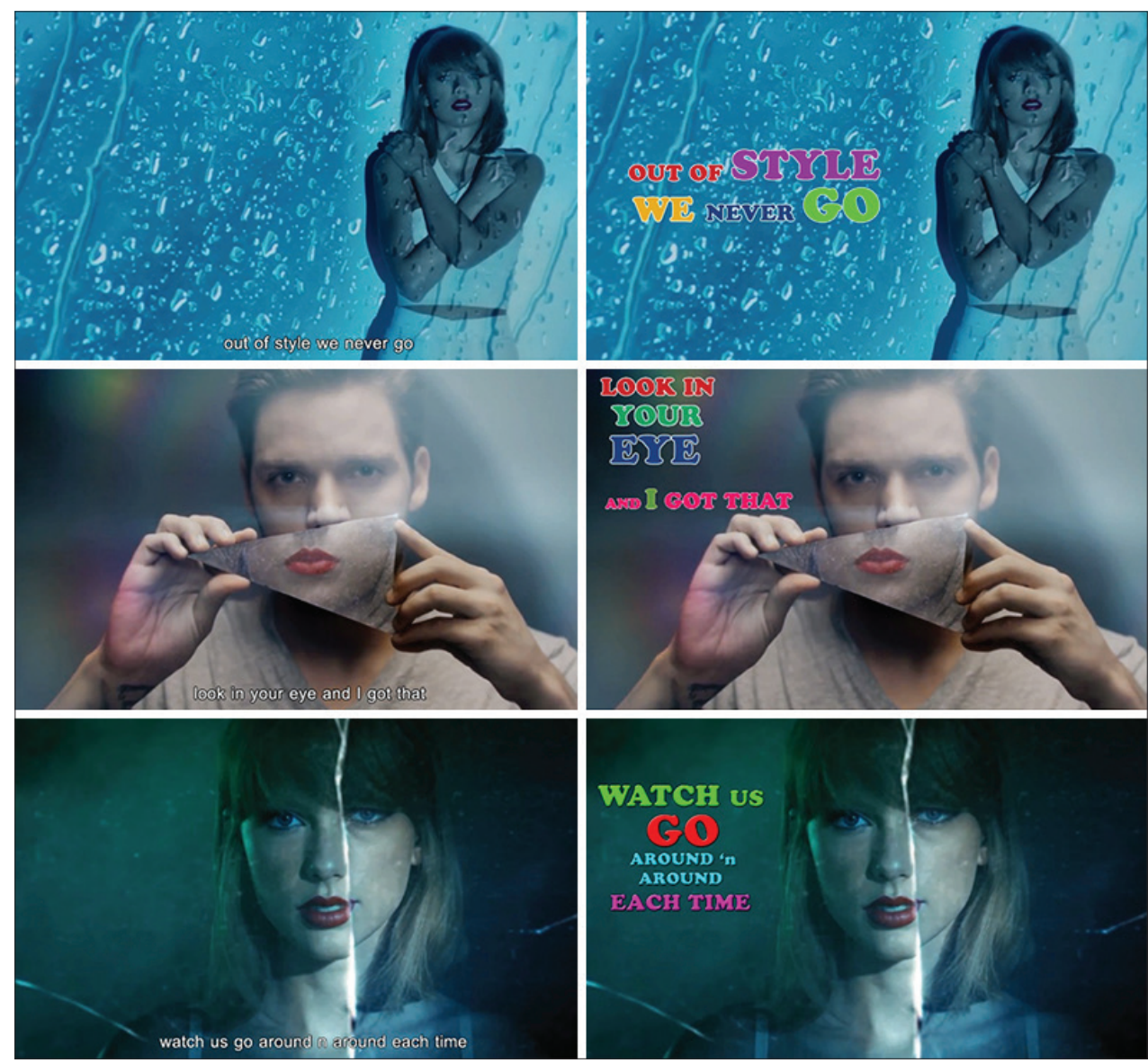

Appendix 1. Screenshots from two versions of the music video 